\title{
Labour intensity of guidelines may have a greater effect on adherence than GPs' workload
}

\author{
Michael J van den Berg*1,2, Dinny H de Bakker1,2, Peter Spreeuwenberg1, \\ Gert P Westert ${ }^{2,6}$, Jozé CC Braspenning33, Jouke van der Zee ${ }^{1,4}$ and \\ Peter P Groenewegen ${ }^{1,5}$
}

Address: ${ }^{1}$ NIVEL, Netherlands Institute for Health Services Research, Utrecht, The Netherlands, ${ }^{2}$ Tilburg University, Faculty of Social and Behavioural Sciences, Tilburg, The Netherlands, ${ }^{3}$ UMC St Radboud, IQ healthcare, Nijmegen, The Netherlands, ${ }^{4}$ Maastricht University, Faculty of Health Sciences, Maastricht, The Netherlands, ${ }^{5}$ Utrecht University, Faculty of Social sciences, Utrecht, The Netherlands and ${ }^{6}$ RIVM, Netherlands Institute for Public Health and the Environment, Bilthoven, The Netherlands

Email: Michael J van den Berg* - M.vandenberg@nivel.nl; Dinny H de Bakker - D.debakker@nivel.nl; Peter Spreeuwenberg - p.spreeuwenberg@nivel.nl; Gert P Westert - Gert.westert@ rivm.nl; Jozé CC Braspenning - J.braspenning@iq.umcn.nl; Jouke van der Zee - j.vanderzee@nivel.nl; Peter P Groenewegen - p.groenewegen@nivel.nl

* Corresponding author

Published: 28 November 2009

BMC Family Practice 2009, 10:74 doi:10.1 |86/147|-2296-10-74
Received: 2 November 2009

Accepted: 28 November 2009

This article is available from: http://www.biomedcentral.com/I47/-2296/10/74

(C) 2009 van den Berg et al; licensee BioMed Central Ltd.

This is an Open Access article distributed under the terms of the Creative Commons Attribution License (http://creativecommons.org/licenses/by/2.0), which permits unrestricted use, distribution, and reproduction in any medium, provided the original work is properly cited.

\begin{abstract}
Background: Physicians' heavy workload is often thought to jeopardise the quality of care and to be a barrier to improving quality. The relationship between these has, however, rarely been investigated. In this study quality of care is defined as care 'in accordance with professional guidelines'. In this study we investigated whether GPs with a higher workload adhere less to guidelines than those with a lower workload and whether guideline recommendations that require a greater time investment are less adhered to than those that can save time.
\end{abstract}

Methods: Data were used from the Second Dutch National survey of General Practice (DNSGP2). This nationwide study was carried out between April 2000 and January 2002.

A multilevel logistic-regression analysis was conducted of 170,677 decisions made by GPs, referring to 4 I Guideline Adherence Indicators (GAls), which were derived from 32 different guidelines. Data were used from $130 \mathrm{GPs}$, working in 83 practices with 98,577 patients. GP-characteristics as well as guideline characteristics were used as independent variables. Measures include workload (number of contacts), hours spent on continuing medical education, satisfaction with available time, practice characteristics and patient characteristics. Outcome measure is an indicator score, which is I when a decision is in accordance with professional guidelines or 0 when the decision deviates from guidelines.

Results: On average, $66 \%$ of the decisions GPs made were in accordance with guidelines. No relationship was found between the objective workload of GPs and their adherence to guidelines. Subjective workload (measured on a five point scale) was negatively related to guideline adherence $(\mathrm{OR}=0.95)$. After controlling for all other variables, the variation between GPs in adherence to guideline recommendations showed a range of less than $10 \%$.

$84 \%$ of the variation in guideline adherence was located at the GAl-level. Which means that the differences in adherence levels between guidelines are much larger than differences between GPs. 
Guideline recommendations that require an extra time investment during the same consultation are significantly less adhered to: $(O R=0.46)$, while those that can save time have much higher adherence levels: $O R=1.55)$. Recommendations that reduce the likelihood of a follow-up consultation for the same problem are also more often adhered to compared to those that have no influence on this $(O R=3.13)$.

Conclusion: No significant relationship was found between the objective workload of GPs and adherence to guidelines. However, guideline recommendations that require an extra time investment are significantly less well adhered to while those that can save time are significantly more often adhered to.

\section{Background}

Physicians' heavy workload is often cited as posing a threat to the quality of care and as a barrier to the implementation of measures to improve quality [1-5]. Although this has often been stated, relatively little effort has been devoted to analysing the relationship between workload and quality of care. In this study we analyse this relationship in a general practice setting. We define workload as the number of consultations handled by GPs within one week. Good quality of care was defined as care in accordance with professional guidelines.

Several studies have cited high workload as a barrier to guideline implementation [6]. However, these studies focus on guideline adherence in general and did not investigate the underlying relationship. Empirical studies on the nature of the relationship between guideline adherence and workload are scarce.

The study of Hutten [1] formed an important first step on this path. However, the data were collected in 1987, when guideline development was still at an early stage. In the past decades the number of professional guidelines has been rising rapidly, so that a better test is possible. More insight into the relationship between workload and guideline adherence can offer valuable information to policy makers and professionals as they strive towards quality improvement.

The purpose of the present study was to investigate the relationship between workload and adherence to professional guidelines. In this we distinguish between the effects of GP workload and the labour intensity of guideline recommendations. We will discuss some theoretical considerations as to why such a relationship is to be expected. This study was carried out in the Netherlands. In the Netherlands guidelines are developed by the Dutch College of General Practitioners. This organisation has a prominent and influential position among GPs. Most Dutch GPs are members of this association and receive all its guidelines and revisions of guidelines. Moreover, the guidelines are published on the internet and are therefore accessible to all who are interested.

\section{The relationship between stress and job performance}

The most plausible assumption appears to be that if workload and guideline adherence are correlated, this correlation will be negative. Workload may be considered to be an indicator for stress due to a lack of time [7]. Psychological research has shown that there is an optimal stress level for workers to perform well [8,9]. A stress level below or above this optimum negatively affects job performance. A number of studies have confirmed the effect of fatigue in clinical settings [10-12].

Consequently, we expect that GPs' workload is negatively related to adherence to professional guidelines.

\section{Why do some physicians adhere better to guidelines than others?}

The acceptance of and adherence to guidelines depends, among other things, on who develops and disseminates them $[13,14]$ and how this is done [15]. The existence of guidelines alone is no guarantee for a change in physicians' behaviour. According to Pathman et al., [16] the process from becoming aware of a guideline to adhering to it, follows four steps: (preawareness) $\rightarrow$ Awareness $\rightarrow$ Agreement $\rightarrow$ Adoption $\rightarrow$ Adherence. Along this path, the process can be hindered. First, a GP must be aware of the existence of the guideline and familiar with the information contained in it (knowledge). Second, the GP must agree with the guideline and be motivated to implement it (attitude). Indeed, some physicians have negative attitudes towards guidelines in general, because they fear these might promote 'cookbook medicine' or decrease their autonomy. Third, physicians must, in practice, be able to act in accordance with guidelines; this can be restricted by external barriers [6].

Workload and time pressure are such barriers that negatively affect the first step in the awareness-to-adherence process, because time is needed to stay informed. GPs with a high workload might spend more time on patient care at the expense of time spent on continuing medical education (CME) or reading specialist literature. Accordingly, they might be less informed about the exact content of guidelines. Therefore, we investigated a possible corre- 
lation between hours spent on CME and guideline adherence and whether this modifies the relationship between workload and guideline adherence.

According to the theory about the stress-job-performance relationship, this relationship depends on an individual response to 'environmental' events. However, different individuals might perceive and experience the same amount of objective workload differently. Not only will the objective workload be of influence but also the experienced workload. This subjective workload may result in a feeling of being in a rush and not having enough time. This experienced lack of time could be more important than the (objective) amount of available time. Therefore, it is to be expected that experienced high workload also negatively affects guideline adherence and probably modifies the relationship between workload and guideline adherence.

\section{Why are some guidelines better adhered to than others?}

Previous research shows that one of the most important characteristics of a guideline to influence compliance is complexity. Guidelines that are easy to understand, can easily be tried out, and do not require specific resources or skills have a greater chance of being used [17-19,15]. It has also been shown with regard to guidelines about prescriptions, that so-called 'don'ts' are better adhered to than 'dos'. Don'ts are recommendations that say not to prescribe something while dos recommend specific drugs [20]. We assume that there is a logical link between the complexity of a guideline and the amount of workload that following this guideline will incur. Since time is scarce for GPs, they will be more likely to adopt guidelines that are simple and less time-consuming. Moreover, GPs with a high workload develop habits and routines to cope with their workload (e.g. spending less time per patient) and might be less likely to change this behaviour even if these routines are in conflict with guidelines. In our study, we also investigate whether guidelines are better adhered to when recommendations are less time-consuming, and whether the negative correlation between workload and guideline adherence is stronger when following the guideline is more time-consuming. Time-consumingness of guidelines was measured as time investment during the same consultation and the chance of return by the patient for the same complaint.

Our research question is: "to what extent is workload an important determinant of guideline adherence?" In this we distinguish between the effects of GP workload and the labour intensity of the guideline recommendations.

\section{Methods \\ Study population}

Data were used from the Second Dutch National Survey of General Practice (DNSGP-2) [21]. This nationwide study was carried out between April 2000 and January 2002, in 104 general practices in the Netherlands, comprising 195 GPs and nearly 400,000 listed patients. In each practice, information about patients, contacts, diagnoses, interventions, referrals, prescriptions etc. were recorded during one year. The data of eight practices were excluded from our analyses because they were deemed insufficient. The study was carried out in keeping with Dutch legislation on privacy. Compliance with privacy regulations was approved by the Dutch Data Protection Authority. The methods and data collection of the DNSGP have been described in greater detail by Westert et al [21].

\section{Data and measurements}

The data file used was created by merging several files with data on different levels. This resulted in a dataset with a multilevel structure. The lowest level consists of decisions by GPs, mostly regarding prescriptions or referrals. This is the dependent variable and will be further clarified under 'measures'. These decisions are nested within patients. This means that every decision was made with regard to a patient, and that more decisions can be made concerning the same patient, but that a specific decision never refers to more than one patient. Patients, in turn, are nested within a GP (every GP has more patients, but a patient always has one GP); GPs are nested within practices. The units at the lowest level (decisions) were not only nested within a specific patient, but also within a specific guideline adherence indicator (GAI), which, for instance, indicates that the decision belongs to the indicator 'referring knee complaints to orthopaedist' or 'prescribing antibiotics for sinusitis'. The data structure of this cross-classified model is visualised in figure 1 .

We will briefly describe the datasets used in this study. These datasets are also summarised in Table 1:

\section{Electronic medical records}

All participating GPs kept electronic medical records. In these records GPs registered the diagnosis using the International Classification of Primary Care (ICPC), and referrals and prescriptions using ATC-codes (Anatomical Therapeutical Chemical classification system).

\section{Patient questionnaire}

A one-page written questionnaire was sent to all listed patients. This included some characteristics which are not registered in the practice administration, such as self-rated health. The response was $76.5 \%$. 


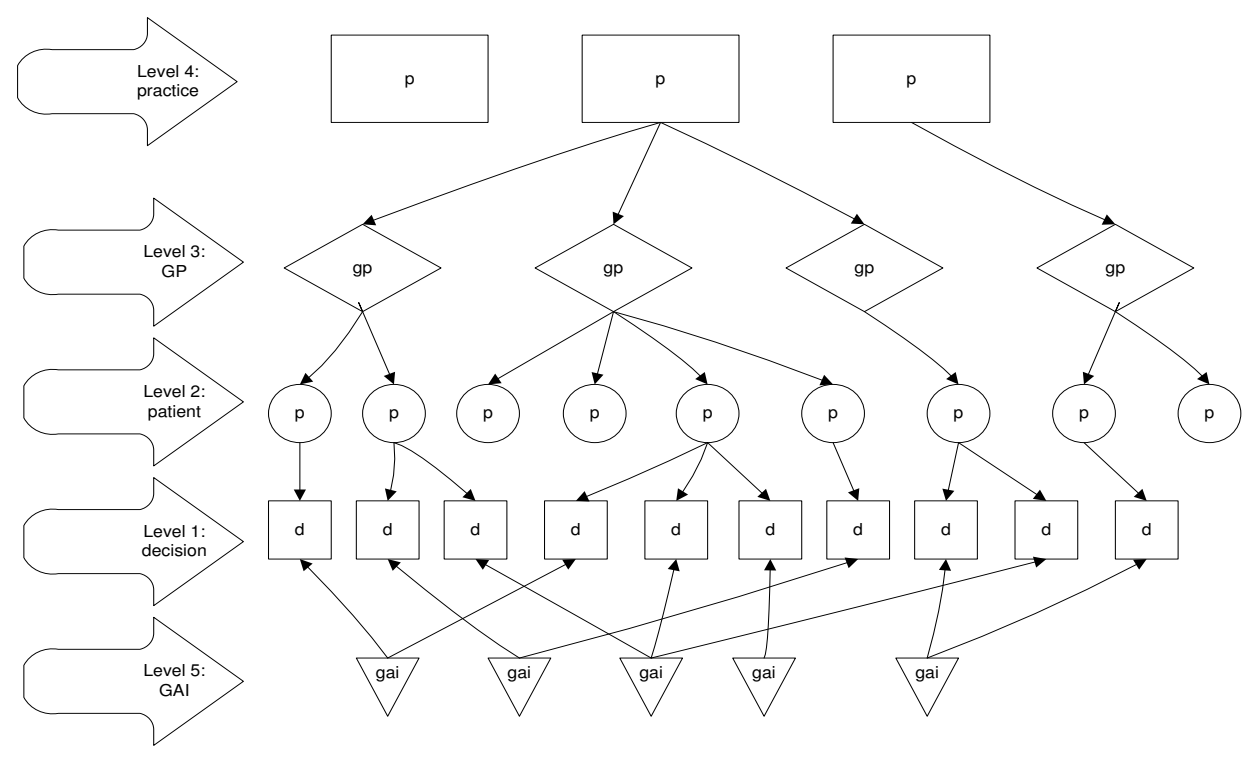

Figure I

Cross-classified multilevel model with decisions nested in GAls and in patients, patients in GPs and GPs in practices

\section{Practice administration}

The practice administration of all participating practices contains a few items of information on all patients on the practice list: sex, date of birth, insurance status and postal code. There were almost 400,000 patients in the DNSGP2.

\section{GP questionnaires}

The GPs received two written questionnaires. The first covered a range of topics about their work. The response to this questionnaire was $96 \%$ (188 GPs). The second questionnaire dealt with workload-related issues and job satisfaction. The response to this second questionnaire was $87 \%$ (164 GPs).

\section{Diaries}

The GPs kept a detailed log of their time use for every quarter of an hour in a representative working week. The diary had a pre-structured form with categories such as 'consultation', 'administration', and 'CME'.

\section{National database of all GPs}

Basic characteristics such as date of birth, sex, singlehanded practice or partnership, etc. were retrieved from the national database of GPs [22].

\section{Expert panel}

Finally, a panel of three practicing general practitioners, working in different practices, was asked to fill out a questionnaire to decide whether a certain decision is associated with a higher or a lower time investment.
All files were merged using unique patient, GP and practice codes for cross-reference between the files. After merging all files, a file with 170,677 records remained, each record representing a decision that was either in accordance with or against a guideline.

All variables used are shown in table 1. In the third column, the type of data source is presented. We will clarify these measures here.

\section{Outcome measure: decision in accordance with guideline}

Electronic medical records were used for the construction of the dependent variable. This variable is dichotomous and indicates whether a decision is in accordance with the guideline (1) or not (0). This was based on a list of 41 Guideline Adherence Indicators (GAI) which were developed by IQ-healthcare $[23,24]$. These indicators were based on clinical guidelines developed by the Dutch College of General Practitioners. Each decision refers to an episode, a patient or a contact. The guidelines refer to a specific diagnosis (e.g. acute sore throat). We will illustrate this with an example: A GP notes as diagnosis 'acute sore throat'. The guideline 'Acute sore throat' advises against the use of antibiotics [25]. If the GP prescribed antibiotics during an illness-episode with the diagnosis 'acute sore throat', this decision is coded ' 0 ' (against guideline) on our dependent variable. If no antibiotics were prescribed, this is coded as ' 1 ' (in accordance with guideline). Obviously, a complete guideline cannot be reduced to one dichotomous variable. Guidelines contain a range of recommendations and considerations that are 
Table I: Variables used in the analyses: mean/\% and standard deviation

\begin{tabular}{|c|c|c|c|}
\hline & Mean/\% & Sd & Type of data source \\
\hline \multicolumn{4}{|l|}{ Dependent } \\
\hline Adherence to guideline & $58.7 \%$ & & Electronic medical records \\
\hline \multicolumn{4}{|l|}{ Independent } \\
\hline \multicolumn{4}{|l|}{ Practice level $(n=83)$} \\
\hline$\%$ publicly insured (per practice) & $65.8 \%$ & $10.1 \%$ & Practice administration \\
\hline$\%$ elderly (per practice) & $6.0 \%$ & $2.8 \%$ & Practice administration \\
\hline$\%$ ethnic minorities (per practice) & $6.3 \%$ & $11.7 \%$ & Patient questionnaire \\
\hline Nat. logarithm \% ethnic minorities & -3.38 & 1.4 & Patient questionnaire \\
\hline$\%$ self-rated health poor (per practice) & $19.0 \%$ & $5.2 \%$ & Patient questionnaire \\
\hline Practice type & & & National database \\
\hline Single-handed & $57.8 \%$ & & \\
\hline Dual practice & $20.5 \%$ & & \\
\hline Group & $12.1 \%$ & & \\
\hline Health centre & $9.6 \%$ & & \\
\hline Urbanization & & & National database \\
\hline Very urban & $20.5 \%$ & & \\
\hline Urban & $24.1 \%$ & & \\
\hline Suburban & $16.8 \%$ & & \\
\hline Rural & $20.5 \%$ & & \\
\hline Very rural & $18.1 \%$ & & \\
\hline Dispensing practice & $10.9 \%$ & & GP questionnaire I \\
\hline \multicolumn{4}{|l|}{ GP-level $(n=130)$} \\
\hline Workload & 114.6 & 35.4 & Electronic medical records \\
\hline Age & 47.4 & 6.15 & National database \\
\hline Sex (female) & $21.5 \%$ & & National database \\
\hline List size & 2018.3 & 545.6 & Practice administration and GP questionnaire I \\
\hline Hours of CME per week & 3.2 & 3.4 & Diaries \\
\hline Satisfaction with available time & 2.9 & 0.7 & GP questionnaire 2 \\
\hline \multicolumn{4}{|l|}{ Patient level $(n=98,577)$} \\
\hline Age & 39.8 & 24.0 & Practice administration \\
\hline Sex (female) & $56 \%$ & & Practice administration \\
\hline Public insurance & $71 \%$ & & Practice administration \\
\hline Self-rated health poor & $18.3 \%$ & & Patient questionnaire \\
\hline Self-rated health unknown & $22.1 \%$ & & Patient questionnaire \\
\hline Non-western ethnic minority & $4.6 \%$ & & Patient questionnaire \\
\hline Ethnicity unknown & $17.8 \%$ & & Patient questionnaire \\
\hline \multicolumn{4}{|l|}{ GAI level $(n=4 I)$} \\
\hline About referrals & $32.0 \%$ & & Electronic medical records \\
\hline Short-term time investment greater & $32.8 \%$ & & Expert panel \\
\hline Short-term time investment smaller & $22.1 \%$ & & Expert panel \\
\hline Long-term time investment greater & $19.1 \%$ & & Expert panel \\
\hline Long-term time investment smaller & $28.6 \%$ & & Expert panel \\
\hline
\end{tabular}

related to each other and that are often ordered in a decision tree. The GAIs measure specific decisions under certain conditions that play a central role in the guideline and that are relatively simple to measure. The selection of these decisions was done by GPs using an iterative consensus procedure. This method was extensively described elsewhere $[23,24,26]$.

In this way, 213,758 decisions were coded referring to 41 GAIs, mainly about prescribing and referrals. These 41
GAIs were derived from 32 different guidelines. We wanted to be sure that all GAIs referred to situations that happen frequently enough to be relevant and to discriminate between GPs. Therefore, a selection was made on the basis of three criteria:

- the numerator must exceed 100 (in the whole database); 
- the indicator must be available for more than 50 practices;

- the denominator divided by the number of practices (which is the average number of times something occurs in one practice) must be higher than 10 .

After this selection, 170,677 records (80\%) remained.

Workload and exactingness of guideline recommendations

- Expected workload effect in actual consultation

The expert panel rated all GAIs on the expected workload in the actual consultation. Every GAI was written as a decision, e.g.: 'prescription of antibiotics to patient with sore throat'. Response categories were 'amount of work in actual consultation is likely to be: greater/equal/smaller'. Some items prescribed a decision that was in accordance with guidelines, other items prescribed a decision that was against the guideline. Answers were recoded into 1, 2 and 3, in such a way that $1=$ higher time investment in actual consultation if the guideline is adhered to and $3=$ smaller time investment in actual consultation if the guideline is adhered to. All GAIs were given the score on the basis of the majority of the expert ratings (two or three). In the case of three different scores, the GAI was scored as 2. This was the case for one indicator. In 32\% there was full agreement between the experts and in $66 \%$ two respondents agreed with each other.

- Expected long-term workload effect

This variable was measured in the same way as expected workload effect in actual consultation. The expert panel was asked to rate the likelihood that the patient will return after this decision (greater/equal/ smaller). Agreement between the experts was somewhat less. In $10 \%$ there was complete agreement, in $68 \%$ two experts agreed and in $22 \%$ three different ratings were given. The GAIs for which there was no agreement, were scored as 'equal' (2).

- Objective workload of GPs
We measured the workload in terms of the average number of consultations during one week. We extracted these data for one year from the electronic medical records of all listed patients.

- Experienced workload (satisfaction with available time)

This variable is an indicator for subjective workload. In the questionnaire, the GPs filled out a job satisfaction scale originally derived from Cranie et al. [27]. Factor analyses showed that four items formed a scale for satisfaction with available time. This scale consists of the four items: satisfaction with time for family, amount of leisure time, time costs of the practice, available time for CME. Response categories were: very dissatisfied, dissatisfied, partly dissatisfied/partly satisfied, satisfied, very satisfied. The higher the score, the higher the satisfaction with the available time. This scale shows reasonable internal consistency (Cronbach's alpha $=0.78)[28]$.

- Number of hours per week spent on Continuing Medical Education (CME)

GPs recorded the number of hours spent on CME in the diaries. CME covers doing courses, visiting conferences or reading professional literature.

List size was computed by averaging the number of patients on the list at the beginning of the year and at the end. This list size on a practice level was divided among the GPs within one practice in proportion to their fulltime equivalents (FTE). Since a proportion of the GPs work part time, it is important to control for list size. Table 2 shows the correlations between the workload related variables on GP level. Only workload (weekly number of consultations) and list size were significantly correlated: 0.58 .

\section{Variables at patient level}

Since decisions made in clinical practice are also affected by patients, we controlled for five patient characteristics: insurance status, age, sex, self-rated health and ethnicity. We used insurance status, age and sex because these variables are always recorded in the medical file and because

Table 2: Bivariate correlations between list size, workload, satisfaction with available time and hours spent on CME

\begin{tabular}{llll}
\hline & & $\mathbf{1}$ & $\mathbf{2}$ \\
\hline 1 & List size & & \\
2 & Workload (weekly number of consultations) & $0.58^{* *}$ & \\
3 & Satisfaction time & -0.11 & -0.07 \\
4 & Hours of CME & 0.10 & 0.05 \\
\hline
\end{tabular}

$*_{p}<0.05 ; *^{*} p<0.005$ 
they are clearly related to care demand in general. Insurance status was coded as 0 (privately insured) or 1 (publicly insured). Insurance status can be considered as a proxy for social economic status, since until 2006, people above a certain income level were insured privately and people below this income level were insured publicly. Publicly insured people, women and elderly have a significantly higher use of care [29]. Moreover, self-rated health was included because people with low self-rated health will more often suffer from more than one disease and will often have more complicated problems. This can be a reason to deviate from guidelines. Self-rated health was originally measured on a scale from 1 (very good) to 5 (very bad); this was recoded into a dichotomous variable. Scores 1 to 3 were recoded into 0 , and scores 4 and 5 (bad and very bad) into 1 . Since this variable has many missing values due to non-response, an extra dummy for 'not known' is used in our analyses. Ethnicity was included in the same questionnaire. This was because previous studies have reported ethnic inequalities in the quality of received care [30] and differences in received prescriptions [31]. Moreover, there can be good reasons to deviate from guidelines when ethnic differences are taken into account [32].

\section{Background variables at GP level}

Age and sex of all participating GPs were collected at the start of the study and were used as controlling variables.

\section{Variables at practice level}

Dispensing practices, urbanization and practice type were used as controlling variables on practice level. Whether the practice was a dispensing practice was included in the models because many of the GAIs deal with prescriptions. In previous research, it has been shown that GPs in dispensing practices prescribe a broader range of drugs [33]. The degree of urbanization was measured on the basis of the addresses of the practices. There are five categories, varying from very urban to rural. Practice type has four categories: single-handed, dual, group and health centre.

Since the work style of GPs and the presented morbidity might also differ according to case-mix and the composition of the patient population, we added four case-mix variables:

Proportion of publicly insured patients, proportion of elderly $(>65+)$, the proportion of patients with a low selfrated health and the proportion of non-western ethnic minorities. To compute these variables, we aggregated the characteristics of all listed or responding (in case of ethnicity and self-rated health) patients. Since the distribution of ethnic minorities was considerably skewed to the left (indicating that ethnic minorities are highly concen- trated within a limited number of practices), this was transformed to a natural logarithm.

\section{Controlling variable at GAl-level}

Prescription/referral: Most GAIs involve prescriptions or referrals. Only three GAIs are related to other decisions. We coded all GAIs as either 0 (prescription or other) or 1 (referral).

\section{Statistical Analyses}

As explained under 'measures' adherence to 41 separate GAIs was combined within one outcome variable. A score of ' 1 ' on this variable means that a GP made a decision that was in accordance with a guideline, a score of ' 0 ' means that a GP decided something that was against a guideline. Yet, since we expect that some recommendations are better adhered to than others, we also computed the adherence per GAI. To get an initial impression of the variance in guideline adherence between GAIs and the differences between GPs with a relatively high and a relatively low workload, the proportion of guideline adherence was investigated per GAI and per workloadquartile.

In our multivariable analyses we used a cross-classified logistic multilevel model.

Our dependent variable refers to acting in accordance with guidelines (1) or deviating from guidelines (0). Explanatory variables were added to the model in five steps:

Model 1: workload

Model 2: Workload + background variables of GPs, practices and patients

Model 3: model 2 + hours spent on CME per week and satisfaction with available time

Model 4: model 3 + GAI-characteristics

Model 5: model $4+$ interaction terms (workload * workload effect in actual consultation) and (workload * workload effect in long term).

The analyses were carried out in the software programme MLwiN.

\section{Results}

Of all decisions in our data, 59\% were in accordance with the guidelines. Figure 2 displays the proportion of cases that was in accordance with guidelines per GAI. In the figure, the average proportion of all GPs is shown, the upper workload quartile (GPs with the highest workload) and 


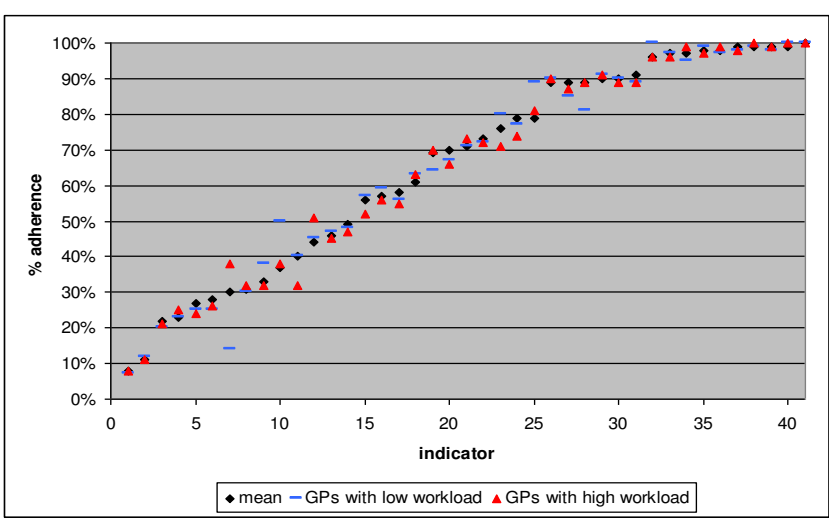

Figure 2

Proportion of cases in accordance with guidelines, per GAl; mean, GPs with relatively high workload (upper quartile) and GPs with relatively low workload (lowest quartile).

the lowest workload quartile (GPs with the lowest workload). Clearly, the variation in adherence between the GAIs is large: between $8 \%$ and almost $100 \%$. There is also variation between GPs, but this variation is smaller. The variation among GPs differs between GAIs with standard deviations between 1.6 and 39.8. In 44\% of the GAIs (18) the adherence was higher among the lowest workload quartile, in 34\% (14) the adherence was higher among the highest workload quartile, in $22 \%$ there was no difference. Accordingly, no clear correlation between workload and guideline adherence was found.

Table 3 shows the multilevel models. Model 1 shows no correlation between adherence and the GPs' workload. In the other models too, no correlation between objective workload and guideline adherence was found. Likewise, the expectation that the time spent on CME is related to guideline adherence was not confirmed since no significant relationship was found. However, a correlation between subjective workload and adherence was indeed found. In contrast to our expectations this correlation is negative (odds ratio of 0.95). Remarkably, the more satisfied GPs are with their available time, the lower their adherence.

Some strong and statistically significant relationships were found between the required time investment of recommendations and guideline adherence. We expected that recommendations that require an extra time investment during the same consultation, would be less well adhered to. This is supported by our findings. Recommendations that require more time in the same consultation are less adhered to: $(O R=0.46$, compared to the 'equal' category). Those that can save time are much better adhered to: $(\mathrm{OR}=1.55)$. Also an expected time investment in the long term is of influence. Recommendations that reduce the likelihood of a follow-up consultation for the same problem are also often adhered to compared to those that have no influence on this (the 'equal' category) $(\mathrm{OR}=3.13)$. Yet, recommendations that increase the chance of a follow-up consultation are also more often followed $(\mathrm{OR}=2.10)$. Recommendations that deal with referrals are significantly more often followed than those concerning prescriptions $(\mathrm{OR}=15.35)$.

No interaction effects were found. This means that the effects found for the GAI recommendations do not differ between GPs with a higher and those with a lower workload. After controlling for all variables, guideline adherence varied between $35.1 \%$ and $43.3 \%$ among GPs.

At the bottom of table 3 the variance components are shown; over 99\% (1.965) of the higher level variance was located at the GAI level. After adding the other variables, some shifts took place between the different components. In our final model, still $84 \%$ of the variance was located at the GAI level; the remaining part was located at the patient level. Figure 3 shows the percentage of adherence, per GP, after controlling for all other variables. As we can see, the differences are relatively small: a range of less than $10 \%$ between the extremes. Note that the scores in the figure are estimated on the basis that all other variables equal 0 . For most variables this was the average score, but also the variables 'about referrals' have a value of 0 in the equation, which means that the score is estimated on the basis that the decision is not related to referrals.

\section{Discussion and conclusion}

The main question in this study was whether there is a relationship between workload and guideline adherence. We did not find any differences in guideline adherence between GPs with a higher and those with a lower objective workload. However, we found marked differences between guideline recommendations that require a time investment and those that require no extra time. Recommendations that require an extra time investment were less well adhered to.

The expectation that the time spent on keeping up to date influences guideline adherence was not confirmed. Again, this is in line with previous results (Hutten [1]). A possible explanation for the absence of this relationship is that the Netherlands has a mandatory credit points based system for CME. A minimum of 40 hours per year is required to retain registration as a GP. Besides, the recommendations in the guidelines are clearly described, easily accessible and mostly deal with frequently occurring complaints. 
Table 3: Multilevel logistic regression analyses of GP-characteristics, practice characteristics, patient characteristics and indicator characteristics on adherence to guidelines

\begin{tabular}{|c|c|c|c|c|c|c|}
\hline & Model 0 & Model I & Model 2 & Model 3 & Model 4 & Model 5 \\
\hline & OR & OR & OR & OR & OR & OR \\
\hline Constant & 1.893 & 1.893 & 1.893 & 1.066 & 0.657 & 0.654 \\
\hline \multicolumn{7}{|l|}{ GP- characteristics } \\
\hline Age & & & 1.001 & 1.002 & 1.004 & 1.004 \\
\hline Female GP (ref = male) & & & 1.007 & 1.021 & 1.022 & 1.024 \\
\hline List size & & & 0.952 & 0.953 & 0.952 & 0.947 \\
\hline Workload & & 1.001 & 1.000 & 1.000 & 1.000 & 1.000 \\
\hline Hours of CME per week & & & & 0.996 & 0.996 & 0.996 \\
\hline Satisfaction with available time (I-5) & & & & & $0.954 *$ & $0.954 *$ \\
\hline \multicolumn{7}{|l|}{ Practice and population characteristics } \\
\hline Proportion of elderly $75+$ & & & $1.024 * *$ & $1.024 * *$ & $1.044 * *$ & $1.045 * *$ \\
\hline Proportion of publicly insured & & & 1.004 & 1.004 & $1.007 *$ & $1.007 *$ \\
\hline Proportion of ethnic minorities (Nat. Logarithm) & & & 1.035 & 1.035 & $1.067 *$ & $1.068 *$ \\
\hline Proportion of self-rated health poor & & & $0.985 *$ & 0.986 & $0.972 * *$ & $0.972 * *$ \\
\hline \multicolumn{7}{|l|}{ Practice type $(r$ ref $=$ single-handed $)$} \\
\hline Dual & & & 1.025 & 1.016 & 1.027 & 1.031 \\
\hline Group & & & 1.037 & 1.015 & 1.008 & 1.006 \\
\hline Health centre & & & 1.024 & 1.010 & 1.030 & 1.033 \\
\hline \multicolumn{7}{|l|}{ Urbanization (ref = very urban) } \\
\hline Urban & & & 1.050 & 1.053 & 1.017 & 1.020 \\
\hline Moderately urban & & & 1.102 & 1.114 & 1.110 & 1.111 \\
\hline Rural & & & 1.008 & 1.006 & 0.992 & 0.999 \\
\hline Very rural & & & 1.062 & 1.075 & 1.106 & 1.119 \\
\hline Dispensing practice & & & 0.999 & 0.984 & 0.933 & 0.931 \\
\hline \multicolumn{7}{|l|}{ Patient characteristics } \\
\hline Age & & & $|.00| * *$ & $1.00 \mid * *$ & $1.002 * *$ & $1.002 * *$ \\
\hline Female $($ ref $=$ male $)$ & & & $1.043 * *$ & $1.043 * *$ & $1.069 * *$ & $1.069 * *$ \\
\hline Publ. Insured & & & 1.016 & 1.015 & 1.020 & 1.020 \\
\hline Self-rated health poor & & & $0.967 * *$ & $0.967 * *$ & $0.956 * *$ & $0.956 * *$ \\
\hline Self-rated health unknown & & & $0.962 *$ & $0.962 *$ & $0.94 I *$ & $0.94 I *$ \\
\hline Non-western migrant (ref = western) & & & 0.979 & 0.979 & 0.956 & 0.955 \\
\hline Ethnicity unknown & & & 1.030 & 1.030 & $1.050 *$ & $1.050 *$ \\
\hline \multicolumn{7}{|l|}{ GAl-characteristics } \\
\hline \multicolumn{7}{|l|}{ Short-term time investment (ref $=$ equal) } \\
\hline Greater & & & & & $0.458 * *$ & $0.461 * *$ \\
\hline Smaller & & & & & $1.547 * *$ & $1.550 * *$ \\
\hline \multicolumn{7}{|l|}{ Long-term time investment ( $r$ ef $=$ equal) } \\
\hline Greater & & & & & $2.104 * *$ & $2.104 * *$ \\
\hline Smaller & & & & & $3.133 * *$ & $3.155 * *$ \\
\hline About referrals (ref $=$ prescriptions and other) & & & & & $15.333 * *$ & I $5.348 * *$ \\
\hline Interaction workload* time investment short greater & & & & & & 0.999 \\
\hline Interaction workload* time investment short smaller & & & & & & 1.000 \\
\hline Interaction workload* time investment long greater & & & & & & 1.000 \\
\hline Interaction workload* time investment long smaller & & & & & & 0.999 \\
\hline \multicolumn{7}{|l|}{ Variance components } \\
\hline Practice level & 0.002 & 0.001 & 0.000 & 0.000 & 0.00 & 0.000 \\
\hline Reduction [I] & & $50 \%$ & $100 \%$ & $100 \%$ & $100 \%$ & $100 \%$ \\
\hline GP-level & 0.005 & 0.003 & 0.003 & 0.003 & 0.007 & 0.007 \\
\hline Reduction [I] & & $32.3 \%$ & $32.3 \%$ & $40.2 \%$ & $0 \%$ & $0 \%$ \\
\hline Patient level & 0.000 & 0.000 & 0.000 & 0.000 & 0.285 & 0.287 \\
\hline \multicolumn{7}{|l|}{ Reduction [I] } \\
\hline GAl level & 1.965 & 1.889 & 1.970 & 1.971 & 1.516 & 1.519 \\
\hline Reduction [I] & & $4 \%$ & $0 \%$ & $0 \%$ & $22.8 \%$ & $22.8 \%$ \\
\hline
\end{tabular}

$\mathrm{OR}=\exp -\mathrm{b}$ (odds ratio); ${ }^{*} \mathrm{p}<0.05,{ }^{* *} \mathrm{p}<0.005$ 


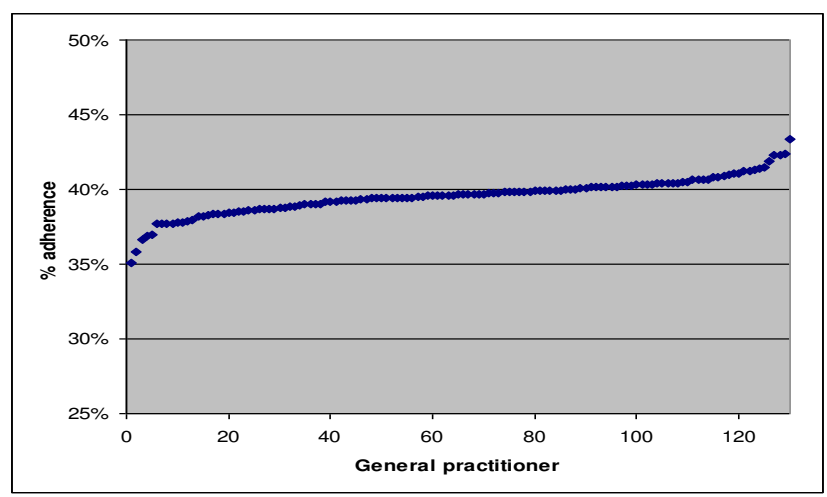

Figure 3

Proportion adherence to guidelines per GP, after correction for all variables.

We did observe a small but statistically significant relationship between experienced lack of time (subjective workload) and guideline adherence. However, the finding runs contrary to our expectation: higher satisfaction with available time is found to be correlated to lower guideline adherence. Zantinge et al. [34] found that GPs who experience a lack of time are less patient-centred. This could possibly lead to a tendency to fall back on guidelines and to provide more 'standard' care. The relationship is, however, very small. A better understanding of this relationship requires further investigation.

The relationship that we found between short-term time investment and adherence is in line with our expectation: recommendations that require more time investment are followed significantly less often; those that reduce the time investment are more often followed. These correlations are quite strong and are statistically significant. We also found that recommendations that are less likely to induce follow-up consultations are more often adhered to. Contrary to our expectation, recommendations that are likely to lead to follow-up consultations are likewise more often followed compared to the 'equal' category. Of course, the GP's choice whether or not to follow guidelines is constrained by medical considerations. Workload is only one factor in the decision process and despite their workload, GPs are obviously concerned for the wellbeing of their patients. This probably explains why recommendations that incur follow-up consultations are better adhered to.

Two important methodological considerations will be discussed here. First, we want to underline the importance of the cross-classified modelling we used. If we had not included the GAI-level, we would have concluded that some GPs have a higher adherence rate than others, with- out noticing that this is due to the simple fact that some GPs have a higher number of contacts that are related to GAIs that are better followed in general. We checked this by repeating the analyses without including GAI-level, which resulted in a considerable variation between GPs.

Second, in the literature about guideline adherence, sometimes a distinction is made between so-called 'dos' and 'don'ts'; recommendations that advise to do something and those that advise not to do something. It may appear obvious that doing something will generate more workload than not doing something and thus, that our expert panel rated the dos as more burdensome than the don'ts. This was, however not the case. Prescribing, for instance, often generates less workload than explaining why the patient does not get a prescription. There was no clear relationship between the expected workload and whether the recommendation was a 'do' or a 'don't'.

Some remarks will be made about the limitations of this study. First, it should be noted that guideline adherence is only a part of the quality of care. Many aspects of quality, such as communication style and organisation are beyond the scope of this study. There is no one-on-one relationship between guideline adherence and quality. In some cases, there are good reasons to deviate from guidelines. These reasons will often be related to patients or to morbidity, but not to GPs and practices. Previous studies have shown that comorbidity can be a reason to deviate from guidelines [15]. This factor was not controlled for in this study. It is, however, unlikely that comorbid conditions will vary strongly between GPs or practices after controlling for age and self-rated health. Second, our data contain only cases that could be measured by an indicator. The content of the guidelines encompasses many more recommendations that were not measured, due to the simple fact that not all GPs actions are recorded in a file. Third, in our analyses, workload was considered a stable characteristic at individual GP level, i.e. some GPs are consistently busier than others. At the same time, workload can also vary between days. Consequently, it seems plausible that the same GP might make other decisions on busy days than on less busy days. To determine how busy a GP was on a specific day, one needs the number of contacts on that day as a numerator and the number of working hours as a denominator. The latter was, however, not known. Fourth, the data used in this study are relatively old. It was, however the most recent database available with this specific information. When more recent data are available, it should be investigated whether the relations that we found have been changing over time. Fifth, there are possibly factors that were not included in our analyses but do influence adherence. These might be individual preferences of patients or specific conditions in the situation of patients that can not be derived from electronic records. 
The finding that the required time investment incurred by a recommendation was strongly correlated with adherence, in combination with the fact that an overwhelming proportion of the variance was located on the GAI level, leads to two important conclusions. First, in the Netherlands, adherence to guidelines seems to depend on the content of the guidelines to a far greater extent than on the GPs. As described in the introduction, a great effort has already been made in the Netherlands to promote and disseminate the guidelines. It is therefore likely that in countries where guidelines have a less firm position, more variation between GPs will be found and that thus, there is more to gain by encouraging GPs to adhere to and to adopt guidelines. Second, when developing guidelines, it seems sensible to take the required time investment of recommendations into account, since this may affect the likelihood that recommendations are followed.

\section{Competing interests}

The authors declare that they have no competing interests.

\section{Authors' contributions}

$\mathrm{MB}$ was involved in the original idea, design, analysis and interpretation of the data and wrote the manuscript. DB was involved in the data collection and the design of the DNSGP and contributed to the interpretation of the data and the critical revision of the manuscript. PS contributed to the statistical analyses and interpretation of the data. GPW was involved in the data collection and the design of the DNSGP, the design of the study and contributed to the critical revision of the manuscript. JCCB directed the development of all quality indicators used in this study and contributed to the critical revision of the manuscript. $\mathrm{JZ}$ was involved in the data collection and the design of the DNSGP and contributed to the critical revision of the manuscript. PPG was involved in the original idea, design, analysis and interpretation of the data and contributed to the critical revision of the manuscript. All authors read and approved the final manuscript.

\section{Acknowledgements}

We would like to thank all the general practitioners who participated in the DNSGP and the GPs that formed the expert panel. The DNSGP was financed by the Dutch ministry of health.

\section{References}

I. Hutten JBF: Workload and provision of care in general practice Utrecht, NIVEL; 1998.

2. Groenewegen PP, Hutten JBF: Workload and job satisfaction among general practitioners: a review of the literature. Soc Sci Med 1991, 32(10): IIII-III9.

3. Rundall TG, Shortell M, Wang MC, Casalino L, Bodenheimer T, Gillies RR, Schmittdiel A, Oswald N, Robinson JC: As good as it gets? Chronic care management in nine leading US physician organisations. BMJ 2002, 325:958-961.

4. Patterson ES, Nguyen AD, Halloran JP, Asch SM: Human Factors Barriers to the Effective Use of Ten HIV Clinical Reminders. Am Med Inform Assoc 2004, I I (I):50-59.
5. Cranney M, Warren E, Barton S, Gardner K, Walley T: Why do GPs not implement evidence based guidelines? A descriptive study. Family Practice 2001, I 8(4):359-363.

6. Cabana MD, Rand CS, Powe NR, Wu AW, Wilson MH, Abboud PC, Rubin HR: Why don't physicians follow clinical practice guidelines? JAMA 1999, 282( I 5): |458-| 465.

7. Jex SM, Beehr TA, Roberts C: The meaning of occupational stress items to survey respondents. Journal of Applied Psychology 1992, 77:623-628.

8. Selye H: Stress without distress New York, McGraw-Hill; 1975.

9. Muse LA, Harris SG, Feild HS: Has the Inverted-U Theory of Stress and Job Performance Had a Fair Test? Human Performance 2003, 4:349-364.

10. Vroom VH: Work and motivation New York, Wiley; 1964.

II. Firth-Cozens J, Greenhalgh J: Doctors' perceptions of the links between stress and lowered clinical care. Soc Sci Med 1997, 44(7): $1017-1022$.

12. Gaba DM, Howard SK: Fatigue among clinicians and the safety of patients. N Engl J Med 2002, 347(16):.

13. Grol R: Successes and Failures in the implementation of Evidence-Based Guidelines for Clinical Practice. Med Care 200 I, 39(8 suppl 2):46-54.

14. Butzlaff M, Kempkens D, Schnee M, Dieterle W, Böcken J, Rieger MA: German ambulatory care physicians' perspectives on clinical guidelines- a national survey. BMC Family Practice 2006, 7:47.

15. Francke AL, Smit MC, De Veer AJE, Mistiaen P: Factors influencing the implementation of clinical guidelines for health care professionals: a meta-review. BMC Medical Informatics and Decision Making 2008, 8:38.

16. Pathman DE, Konrad TR, Freed GL, Freeman VA, Koch GG: The Awareness-to-Adherence Model of the Steps to Clinical Guideline Compliance. The Case of Paediatric Vaccine Recommendations. Med Care 1996, 34(9):873-889.

17. Rogers EM: Diffusion of innovations 4th edition. New York, Free Press; 1995.

18. Rogers EM: Lessons for guidelines from the diffusion of innovations. Jt Comm J Qual Improv 1995, 2 I:324-328.

19. Grilli R, Lomas J: Evaluating the message: the relationship between compliance rate and the subject of a practice guideline. Med Care 1994, 32:202-213.

20. Braspenning J, Schellevis F, Grol R: Kwaliteit in beeld. Medisch Contact 2004:2I.

21. Westert GP, Schellevis FG, De Bakker DH, Groenewegen PP, Bensing $J M$, van der Zee J: Monitoring health inequalities through General Practice: the Second Dutch National Survey of General Practice. European Journal of Public Health 2005, I 5:59-65.

22. NIVEL: Professions in healthcare. [http://www.nivel.nl/
[ beroepenindezorg].

23. Braspenning JCC, Schellevis FG, Grol RPTM: Kwaliteit huisartsenzorg belicht Utrecht, NIVEL; 2004.

24. Braspenning J, Schellevis F, Grol R: Assessment of primary care by clinical quality indicators. In Morbidity, Performance and Quality in Primary Care; Dutch General Practice on stage Edited by: Westert GP, Jabaaij L, Schellevis FG. Oxford, Radcliffe Publishing; 2006: 195-204.

25. Zwart S, Dagnelie CF, Van Staaij BK, Balder FA, Boukes FS, Starreveld JS: NHG-standaard acute keelpijn. Huisarts Wet 2007, 50(2):59-68.

26. Campbell SM, Braspenning J, Hutchingson A, Marshall M: research methods used in developing and applying quality indicators in primary care. Qual Saf Health Care 2002, I I (4):358-364.

27. McCranie EW, Hornsby JL, Calvert JC: Practice and career satisfaction among residency trained family physicians: a national survey. J Fam Pract 1982, I4(6): I I07-I I I4.

28. van den Berg MJ, Kolthof ED, de Bakker DH, van der Zee J: The workload of general practitioners [De werkbelasting van huisartsen]. Utrecht, NIVEL; 2004.

29. LINH: [Netherlands Information Network of GeneralPractice] [http://www.linh.nl]

30. Urbanus-van Laar JJN: Ethnic inequalities in quality of care for children in the Netherlands Amsterdam, Academic Medical Centre- University of Amsterdam; 2007.

31. Van Dijk L: Geneesmiddelengebruik verschilt tussen allochtonen en autochtonen. Huisarts Wet 2003, 46(9):.

32. Manna DR, Bruijnzeels MA, Mokkink HGA, Berg M: Ethnic specific recommendations in clinical practice guidelines: a first exploratory comparison between guidelines from the USA, 
Canada, the UK, and the Netherlands. Qual Saf Health Care 2003, I 2:353-358.

33. De Bakker DH, Coffie DSV, Heerdink ER, Van Dijk L, Groenewegen PP: Determinants of the range of drugs prescribed in general practice: a cross-sectional analysis. BMC Health services Research 2007, 7:.

34. Zantinge EM, Verhaak PFM, De Bakker DH, Kerssens J], Meer K Van der, Bensing JM: The workload of general practitioners does not affect their awareness of patients' psychological problems. Patient Education and Counselling 2007, 67:92-99.

\section{Pre-publication history}

The pre-publication history for this paper can be accessed here:

http://www.biomedcentral.com/1471-2296/10/74/pre pub

Publish with Bio Med Central and every scientist can read your work free of charge

"BioMed Central will be the most significant development for disseminating the results of biomedical research in our lifetime. "

Sir Paul Nurse, Cancer Research UK

Your research papers will be:

- available free of charge to the entire biomedical community

- peer reviewed and published immediately upon acceptance

- cited in PubMed and archived on PubMed Central

- yours - you keep the copyright

Submit your manuscript here:

http://www.biomedcentral.com/info/publishing_adv.asp
BiolMedcentral 